\title{
AN EXPLORATORY STUDY OF “BEST PRACTICE” IN ENVIRONMENTALLY SUSTAINABLE EVENT MANAGEMENT IN AUSTRALIAN PUBLIC EVENTS
}

\author{
ROB HARRIS AND KATIE SCHLENKER \\ University of Technology Sydney, UTS Business School, Australian Centre for Event Management, \\ Sydney, Australia
}

This study seeks to provide insights into "best practice" in the area of environmentally sustainable event management in Australian public events. In performing this role, it aims to: determine forces acting to drive engagement with environmental management practices; identify the key challenges event owners and managers face in seeking to adopt such practices; determine types of environmentally sustainable practices currently in use; establish how events are measuring their environmental performance; and identify those factors serving to facilitate or inhibit engagement by events with an environmental agenda. The article begins with a literature review of research germane to the study, along with an overview of the methodology employed. Key findings emerging from the application of this methodology suggest that actions in this area: have increasingly become an aspect of overall event planning; target multiple areas with the potential to generate environmental impacts; are driven primarily by organizer values and attendee and community expectations; and face constraints linked largely to the availability of resources, expertise, and time. This article acknowledges that the planning and delivery of environmentally sustainable events has become one of the critical challenges facing public event management, and as such it seeks to make a meaningful contribution to both the growing academic literature in this area, and equally importantly, to industry practice.

Key words: Environmentally sustainable event management; Public events; Critical issues; Best practice; Environmental impacts; Australia

Introduction

Although economic and, to a lesser extent, social impacts of events have been the subject of researcher interest for some time, the matter of event environmental effects and their associated management has remained, up until relatively recently, a little explored area (Arcodia, Cohen, \& Dickson, 2012; Collins, Munday, \& Roberts, 2012; Getz, 2010; Laing \& Frost, 2010; Yuan, 2013). However, this situation is changing with several texts (Goldblatt, 2012; Jones, 2014; Raj \& Musgrave, 2009) along with a small but growing number of research articles (e.g., Andersson \& Lundberg, 2013; Collins \& Cooper, 2017; 
Harvey, 2009; Laing \& Frost, 2010; Mair \& Laing, 2012; Wong, Wan, \& Qi, 2014; Zifkos, 2015) focusing on this aspect of event management.

The expanded interest of researchers in the environmental impacts of events parallels the actions of public event owners and managers themselves who are increasingly seeking to minimize the environmental impacts that result from their events. The reasons for this lie in the rising expectations of audiences, sponsors, and other stakeholder groups, as well as increased input costs (Adema \& Roehl, 2010; Jones, 2014). An increasing level of awareness and actions around environmental sustainability confirm this as one of the critical challenges facing those responsible for planning and delivering public events.

To aid public event managers and owners in their efforts to enhance the environmental sustainability of their events, published materials, programs, and organizations providing advice in this area have been developed/established. For example, there are several international environmental initiatives by the United Nations Environment Program (UNEP) in the sport and music event fields (Rodrigues, 2016; UNEP, n.d.) and an international standard for sustainable event management-ISO 20121 (International Standards Organization [ISO], 2015). Additionally, advice, publications, and other resources are now freely available from organizations specializing in reducing the environmental footprint of events, most notably from the Sustainable Event Alliance (2018), Event Industry Council Sustainability Initiative (2017), and A Greener Festival (2017).

The intent of this article is to contribute to this emergent area of research and practice by examining how a selection of "best practice" public events in Australia have approached the challenge of planning and delivering "green" events. Specifically, it explores: the forces driving the adoption of environmentally sustainable practices; the challenges faced by event owners and managers in seeking to make their events more environmentally sustainable; the range of environmentally sustainable practices currently in use; approaches being used to measure the environmental performance of events; and factors serving to hinder or facilitate engagement by event owners and managers with an environmental agenda. In doing so, this study contributes to a small but growing body of literature that aims to develop an understanding of current practice in environmentally sustainable event management, with a view to assisting those charged with the increasingly critical issue of framing "best practice” environmental sustainability strategies for public events.

\section{Background}

To provide a clear understanding of the focus of this article it is useful to firstly define two associated key concepts, specifically public events and environmental sustainability. The former, while often used in the context of certain types of events such as festivals, national celebrations, exhibitions, expositions, and fairs, is rarely defined. This being the case, and for the purposes of this study, the term will be used to refer to an event that is: created with the general public (or a specific subgroup of the general public) in mind; one time or periodic; ticketed or free; and conducted for one or more of the following purposes-entertainment, fund/revenue raising, education, cultural enhancement, or awareness/support raising. Although the previously-cited examples of events fall within this definition, it is also possible that other types of events, such as conferences, depending on their target audience(s), might on occasion be described in this way.

The concept of environmental sustainability has been variously defined (e.g., Goodland, 1995; Moldan, Janouskova, \& Hak, 2012; Morelli, 2011). These definitions, when viewed collectively, indicate that the term is generally used to refer to purposeful efforts intended to maintain environmental functions that support human welfare and natural systems more generally. This focus is reflected in the literature in this area, which deals with the maintenance of biodiversity and ecosystems, and the processes and practices linked to conservation of water, air, and land resources (e.g., Ekins, 2011; Morelli, 2011; Sutton, 2004).

The conduct of public events, as with many other human activities, has the potential to affect the biophysical environment, and as such the issue of their environmental sustainability is one that warrants examination. Various writers in the event management field have in recent years turned their 
attention to this matter. Although a number of studies have sought to identify event-related environmental impacts (e.g., Andersson \& Lunberg, 2013; Bottrill, Papageorgiou, \& Jones, 2009; Collins \& Cooper, 2017; Dávid, 2009), relatively few have acted to identify the range of actions available to events seeking to reduce such impacts. Of these latter studies, some are case specific (e.g., Collins \& Flynn, 2008; Harvey, 2009; Izawa, 2012), while others (e.g., Gallagher \& Pike, 2011; Mair \& Laing, 2012; O’Rourke, Irwin, \& Straker, 2011) examine multiple events, often of a specific type (e.g., music festivals). In exploring this matter, some researchers have sought to place event environmental impacts into broad groupings, as has been done in this study, as a prelude to discussing management practices. For example, Dávid (2009) discussed environmental sustainability approaches using the groupings waste, transport, programs, water and sewerage, energy, food consumption, and accommodation. Allen, O’Toole, Harris, and McDonnell (2011) proposed a not dissimilar listing that embraces purchasing, energy use, waste management, transport, and water management. Jones (2014) is another that has sought to categorize key areas where events can act to reduce their environmental impacts, and while these areas align with those previously noted, she also draws attention to the matter of destination and venue selection.

Although researchers have increasingly turned their attention to examining environmental sustainability in public event settings, it is also the case that many public events themselves have sought a stronger engagement with the concept. Evidence for this can be found in the numerous published examples of actions taken by events in this area (e.g., Allen et al., 2011; Jones, 2014; Wrap, 2018). In turn, this increased engagement has been driven by several factors. Some writers have identified commercial benefits, in particular cost savings in the areas of energy, water usage, waste disposal, and material usage, as being significant in "pushing" events to reduce use of resources (Harvey, 2009; Jones, 2014; Merrilees \& Marles, 2011). Others have noted the potential an environmental agenda holds for market place differentiation or reputation enhancement (Henderson, 2011). Still others have cited broader community environmental concerns that have resulted in demand for "greener" events
(Mair \& Laing, 2012). Indeed, the emergence of an international standard (ISO, 2015) in sustainable event management in 2012 can arguably be seen as evidence of this demand (Jones, 2014). It can also be observed that some events are going beyond a focus on their own environmental impacts and are actively seeking to play a role in shaping attendee attitudes and behaviors towards the environment more generally. Examples of this include the incorporation of environmental presentations and other environment-based educational activities into event programs (Harris, 2010; Mair \& Jago, 2010; O’Rourke et al., 2011).

Another force of note serving to move public events towards the adoption of more sustainable practices is the need to develop and maintain positive relationships with their respective host communities. For example, the use by events of public assets such as parks, halls, and streets carries with it the potential for negative impacts such as increased traffic, noise and light pollution, and physical damage, all of which have the capacity to jeopardize the future use of these community resources (Allen et al., 2011; AsiaOne, 2016).

Although the previously-cited factors have resulted in an increasing number of public event owners and managers seeking to pursue, to varying degrees, an environmental sustainability agenda, as Mair and Laing (2012) noted, there can be "hurdles or difficulties” (p. 694) in doing so. Cost, or at least the perception that the adoption of environmental practices will result in increased expenditure, can be a significant restraint on action in this area (Pelham, 2011). Concerns as regards costs are understandable given some "green" technologies (e.g., solar power installations and environmentally friendly sewerage treatment systems) have medium to longer-term payback periods, which can place them out of the financial reach of many events (Mair \& Laing, 2012; Stettler, 2011). This raises the issue of scale, and the associated capacity of an event to dedicate resources to sustainability practices (Laing \& Frost, 2010; Lawton \& Weaver, 2010). There is also a cost in terms of the time it takes to introduce, acquire operational skills and knowledge, and manage such technologies (Pelham, 2011). Complicating the use of "green" technologies is the limited time frame in which events operate that can reduce their ability to maximize 
the environmental benefits and cost reductions that flow from their use (Mair \& Jago, 2010).

Other factors can also play a role in the context of limiting the actions of event owners and managers in engaging with an environmental sustainability agenda. Jones and Scanlon (cited in O'Rourke et al., 2011) suggested that at times, event owners and managers can struggle to identify and access contractors, venues, and suppliers with the capacity to participate in their environmental sustainability efforts. Additionally, some practices may not directly reward event owners or managers implementing the practice, as is the case when actions to reduce waste or energy in a venue context produce cost savings for the venue only (Mair \& Laing, 2012). There is also evidence that some event owners and managers do not fully understand, value, or have a desire to acquire information about practices linked to environmental sustainability (Paterson \& Ward, 2011; Stettler, 2011). Given this, it is noteworthy that a study by Robertson, Rogers, and Leask (2009) found that a not insubstantial number (18) of the 60 festival directors they interviewed saw "negative effects on the environment being of no significance to their event" (p. 165).

It is not only event managers and owners whose engagement with sustainable practices can be problematic in terms of reducing event impacts; attendees themselves can present issues. For example, failure of patrons to take their waste with them after an event, to appropriately place it in bins marked for different forms of waste, or to respond to efforts to use public transport, can compromise environmental initiatives (Harvey, 2009; Izawa, 2012; Mair \& Laing, 2012; Stettler, 2011).

Although there are several potential impediments to the efforts by events seeking to reduce environmental impacts, there are also actions that can be taken to enhance the likelihood of success. For example, Harvey (2009) emphasized the importance of creating a "green team" of suppliers, venue/site owners, and attendees to progress an event's environmental efforts. The value of such stakeholder engagement efforts is also emphasized by Andersson and Getz (2008) and Laing and Frost (2010). Harvey (2009) also pointed to the importance of "buy in from the top" in driving environmental sustainability efforts, a factor that Stettler (2011) also found to be key to success in this area.
Indeed, as Mair and Laing (2012) identified in the context of festivals, if management places a high value on managing their event's environmental impacts, it is likely they will develop plans and policies that underpin action in the area. This finding aligns with Yuan's (2013) assertion that event organizers need to be values driven if they want to drive an effective environmental sustainability agenda through their events.

Other factors have also been linked to the effectiveness of event owners and managers in pursuing an environmental sustainability agenda. The adoption of an environmental theme, whether an overarching or secondary event theme, has been found to push events to align their operational practices with environmental considerations (Draper, Dawson, \& Casey, 2011; Lawton, 2009; Mair \& Laing, 2013). Involvement by public events in external environmental initiatives, such as the previously cited International Standards Organization "Event Sustainability Management Standard” (ISO, 2015), and A Greener Festival's "Green Event and Festival Awards" (2017), can also be said to play a role in focusing event owners and managers on environmental outcomes. The development of key performance indicators (e.g., energy usage levels; extent of renewable energy used; waste generated; volume of carbon generated; attendee travel modes) in areas where environmental impacts occur is another means by which public event owners and managers can direct their efforts in this area (Gallagher \& Pike, 2011; Jones, 2014; Lamberti, Fava, \& Noci, 2009).

Acknowledging the extant literature and the emerging engagement by event owners and managers with the concept of environmental sustainability, this study seeks to contribute to both research and practice by examining how a selection of "best practice" Australian public events have applied themselves to the critical challenge of environmentally sustainable event management.

\section{Method}

The sampling approach used in this study can be defined as purposive in nature (Rapley, 2013) and designed to identify what Patton (2002) defined as "information rich" cases of the matter being explored. This technique is appropriate in instances where the intention is to identify particular cases 
of a phenomenon for in-depth investigation, rather than to generalize across an entire population (Neuman, 2003). In employing this approach, the assistance of the Sustainable Event Alliance (SEA), an organization that seeks to facilitate global collaboration, networking, and promotion of best practice in sustainable event management was sought. This body acted to contact its Australian-based members and request that they nominate public events they deemed to be employing "best practice" in the area of environmentally sustainable event management. The concept of "best practice" was defined for this purpose as methods or techniques that were acting to produce significant and meaningful positive environmental outcomes either in specific or multiple areas of an event's operations. These areas were based on those previously employed by various writers identified in the study's literature review and comprised: attendee behavior/education; waste; energy usage; water usage; transport; greenhouse gas emissions; contractor management; procurement; and biodiversity/site environmental protection. Through this means, 42 public events were identified and later contacted by phone and asked to participate in the study. All events contacted agreed to participate, and were asked to nominate a suitably qualified person (e.g., staff member, owner, or organizing committee member) capable of providing a detailed understanding of the efforts of its owners or management in the area of environmental sustainability.

The study's literature review was used to provide the foundation for the development of an online questionnaire for distribution to participating events. The questionnaire comprised four sections. Section one sought details on the event, specifically its duration, the number of attendees, type, location, and budget. Section two asked for details of the event's current environmental sustainability practices, first through four closed-ended questions and then through open-ended questions that required responses concerning specific actions in each of the key environmental impact areas of: attendee behavior/education; waste; energy usage; water usage; transport; greenhouse gas emissions; contractor management; procurement; and biodiversity/site environmental protection. In section three, respondents were asked, using a rating scale, about factors serving to facilitate or inhibit their efforts at engaging with environmental sustainability practices. Finally, section four included a closed-ended question on the methods used to measure event environmental impacts, followed by a series of open-ended questions designed to elicit perspectives on the current state of the public events sector as regards environmental sustainability, including the issues that were being confronted, and how environmental sustainability might be more effectively engaged with. A final open-ended question allowed respondents to raise any other issues with regards to environmentally sustainable public event management.

The questionnaire was piloted by sending it to a selected group of academics and industry experts drawn from members of the SEA. These individuals were asked to consider the questionnaire's length, layout, content, ease of completion, and clarity of question wording. Feedback obtained through this means was then used to make amendments to the questionnaire prior to its distribution in January 2015. The online survey program Qualtrics was used for this purpose. Data collection took place over a period of 2 months, and in order to increase the number of responses from participating events, they were contacted by phone on up to two occasions. This process resulted in 31 responses; however five of these (even after several follow-up calls) contained insufficient information to be included in the study. This left a total of 26 useable responses.

Questionnaire responses were analyzed using SPSS predictive analytics software. Descriptive and analytical statistics were employed to investigate and interpret the data. The qualitative software program NVivo was used to aid in the analysis and associated coding of the qualitative data gained from open-ended questions. Through these means, the researchers gained familiarity with the data, allowing for the identification of emerging themes and concepts. Although the existing literature provided a source of potential themes around which to interpret the data, the researchers found, as Thornberg and Charmaz (2013) had observed, that themes emerge from an analysis of the text itself.

It should be noted that the small sample size used in this study would be a limitation if its intent had been to generalize its findings across all public events. However, given that this inquiry was exploratory in nature, and intended to both 
develop an appreciation of what currently constitutes "best practice" in an area of evolving concern to event owners and managers, and to raise matters that might be further explored through more focused studies, this limitation was not seen by the researchers as significantly affecting the overall value of the findings. Further, given a purposive sampling approach was employed that sought out "information-rich" cases (Patton, 2002), the pool from which the sample could be drawn was inherently limited. Although acknowledging that a degree of bias can result from this approach, this was mitigated against by the use of "experts," in this case SEA members, to identify study participants. Such a mitigation strategy can be an effective means of guarding against inappropriate sampling practices (Rapley, 2013).

\section{Findings}

\section{Sample Characteristics}

Of the events that make up the sample for this study, most were held in New South Wales (38.5\%), followed by Victoria (23.1\%), Queensland and Western Australia (11.5\% each), and South Australia and the Australian Capital Territory (7.7\% each). The majority were festivals (69.2\%), with fewer sporting events (11.5\%), community events (11.5\%), and conferences (7.7\%). Of the events, $46 \%$ were run by not-for-profit (NFP) organizations, and the remainder were government and privatelyrun events (27\% each). Those who responded to the survey held various positions within their event organization: Event manager (23\%); Event director (12\%); Production manager, General manager and Sustainability officer (8\% each); Operations manager (4\%); and not stated (37\%). In exploring the reasons for such a high number of participants not stating their position, it appears that a number of event managers assumed only people in their position were being asked to participate in the study and so the question was therefore considered redundant.

The size of participating events varied, with $34.6 \%$ of events having fewer than 5,000 attendees, $38.4 \%$ having between 5,001 and 20,000 attendees, and $26.9 \%$ having over 20,000 attendees. The sample included 1-day events (23\%), 2-3-day events
(46\%), and 4-5-day events (27\%). Only 4\% of events ran for more than 5 days. The majority of events (53.8\%) were held at a green field site (e.g., public parkland or private farmland), with $30.8 \%$ held on a site owned by the organizers, $7.7 \%$ held at a stadium or showground, and $7.7 \%$ held in venues located in urban settings. In general, participating events had large production budgets with $42.3 \%$ spending over $\$ 500,000$. At the other extreme, $19.1 \%$ of respondents had a production budget of less than $\$ 100,000$.

\section{Forces Serving to "Push" Events Towards the Adoption of Environmentally Sustainable Practices}

Various forces were identified as acting to drive responding events down the path of environmental sustainability (see Table 1). The highest mean rating was for the role that the organization's own operating philosophies/values played (4.36). It can also be seen from this Table that expectations of both attendees (3.72) and the local host community (3.16) were significant. It is noteworthy that reductions in event production costs did not feature strongly. This would seem to indicate that actions in this area are being driven by nonfinancial considerations.

\section{Key Challenges}

In addition to the factors underpinning the adoption of environmentally sustainable practices, events were asked to cite (up to a maximum of three)

Table 1

Considerations Driving the Adoption of Environmentally Sustainable Practices $(n=26)$

\begin{tabular}{lr}
\hline Considerations & Mean \\
\hline Event organization operating philosophies/values & 4.36 \\
Expectations or requirements of attendees & 3.72 \\
Expectations or requirements of local community & 3.16 \\
Expectations or requirements of council & 2.72 \\
Expectations or requirements of promissory/ & 2.56 \\
$\quad$ regulatory bodies & \\
Reduction in event production costs & 2.52 \\
Expectations or requirements of sponsors & 2.36 \\
\hline Note. Mean scores measured on a scale where $1=$ not at all; \\
2= to a small extent; 3 = to a moderate extent; $4=$ to a large \\
extent; 5 = to a very large extent.
\end{tabular}


major challenges they faced in progressing an environmental sustainability agenda. Responses were consolidated and the 10 most cited responses are given in Table 2. Given the volume of waste that events can generate, the appearance of this issue as the number one concern (for $50 \%$ of respondents) is perhaps not surprising. Energy also features significantly here as the second key challenge (for $46 \%$ of respondents) and attendee attitudes and behavior was the third most cited challenge (by 38\% of respondents).

The open-ended comments associated with these challenges provide further insights into their nature. With respect to waste management, respondents repeatedly linked this to other stakeholders, noting the difficulty with getting other parties to comply with waste reduction initiatives. Indicative issues were the difficulties faced in getting vendors to comply with waste initiatives, including the sale of only environmentally friendly products, and sponsors wanting to hand out unsustainable items that had only a one-off use. As regards energy, limitations highlighted in this area were the lack of control events had over hired venues and the expanded energy usage (and associated greenhouse gas generation) associated with event growth. In the context of attendee attitudes and behaviors, difficulties were noted in engaging attendees with aspects of an event's practices in the environmental area, most particularly in the area of waste. In a more general sense, the broader role of how to effectively leverage events to bring about behavioral change beyond the event itself was noted by several respondents. Indicative of such comments is that of one respondent who stated that "we see our main challenge as educating the mainstream population in a way that is enjoyable rather than 'finger shaking' so people feel encouraged to change their daily life habits."

\section{Environmentally Sustainable Practices}

Before asking respondents to identify their environmental sustainability practices, they were requested to indicate the time (in years) over which they had been undertaking practices in this area. An overwhelming majority (76.9\%) indicated they had been active in this area for more than 5 years, with $15.4 \%$ active between $1-2$ years and $7.7 \%$ for $3-4$ years. This result indicates that most participating events had a significant level of experience with the implementation of environmental practices. It can also be seen in Table 3 that there appears to be a relationship between the size of an event's budget and the length of time it has been employing environmentally sustainable practices. This suggests that the availability of financial resources might play a role in the degree to which events are engaging in environmental initiatives.

The role of values and principles in guiding the efforts of sampled events in the employment of environmental practices was found to be of major importance, with some $88.5 \%$ indicating that these had been established, while a further $7.7 \%$ reported

Table 2

Top 10 Challenges in Pursuing Environmental Sustainability ( $n=26$, Multiple Responses Permitted)

\begin{tabular}{lcc}
\hline Challenges & No. of Responses & \% of Respondents \\
\hline Waste reduction/management & 13 & $50 \%$ \\
Energy options, consumption and reduction & 12 & $46 \%$ \\
Attendee attitudes and behavior & 10 & $38 \%$ \\
Cars/transport & 8 & $31 \%$ \\
Stakeholder compliance (and sourcing) & 8 & $31 \%$ \\
Resources (financial, human) & 4 & $15 \%$ \\
Water consumption & 3 & $12 \%$ \\
Local government & 3 & $12 \%$ \\
Measurement of environmental practices & 2 & $8 \%$ \\
Printing (paper use) & 2 & $8 \%$ \\
\hline
\end{tabular}

Note. Challenges that were only mentioned once were: resident accessibility, extreme weather events, inertia, increased attendee numbers, volunteers, perceived difficulty, upper management, noise management, lack of public recognition, and venue restrictions. 
Table 3

Years Active in the Implementation of Environmentally Sustainable Practices by Event Budget $(n=26)$

\begin{tabular}{lccrr}
\hline & \multicolumn{3}{c}{ Number of Years } & \\
\cline { 2 - 4 } Event Budget & $1-2$ & $3-4$ & $>5$ & Total \\
\hline$<\$ 99,999$ & $60 \%$ & $20 \%$ & $20 \%$ & $100 \%$ \\
$\$ 100,000-\$ 499,999$ & $11 \%$ & 0 & $88.9 \%$ & $100 \%$ \\
$>\$ 500,000$ & 0 & $9.1 \%$ & $90.9 \%$ & $100 \%$ \\
\hline
\end{tabular}

that the development of these was "under consideration.” Only 3.8\% reported not having set values or principles to guide their efforts in this area. It was also found, not surprisingly given the previous result, that the majority of events (69.2\%) had progressed to establish an event environmental sustainability/environmental management policy or plan, while another $23.1 \%$ stated this was "under consideration." Only $7.7 \%$ of events had yet to move in this direction.

Using preestablished groupings, events were asked to indicate into which categories their current sustainable actions fell. As is evident from Table 4, nearly all were active in the context of waste management (96.2\%), with the majority taking actions in the areas of attendee behavior (76.9\%), transport (73.1\%), energy (69.2\%), and water (61.5\%). The areas of greenhouse gas emissions $(57.7 \%)$, contractor management (57.7\%), and procurement (50\%) also feature strongly. The relatively low figure (30.8\%) for biodiversity/site environmental protection may be due to the fact that a number of sampled events do not make use of sites/venues where this consideration is relevant.
Figures 1 and 2 detail the range of environmentally sustainable practices in use by the sampled events. Across the key areas of attendee behavior/ education, waste, energy usage, water usage, transport, greenhouse gas emissions, contractor management, procurement, and biodiversity/site environmental protection, the environmental practices in use were found to be underpinned by similar considerations. The first of these was impact minimization. This was evidenced by practices designed to minimize, for example, the use of energy resources, the generation of waste, and water usage at an event. Secondly, there was an appreciation of the need for organizational learning and improvement. The use of practices such as waste audits, benchmarking against established resource use objectives and staff/volunteer training reflect this. Thirdly, there was an acceptance of the value of developing policies, procedures, guidelines, and communication tools to direct not only the actions of the event, but also those of other stakeholders including suppliers, stallholders, contractors, and attendees. Examples of this include the incorporation of environmental criteria into supplier contracts, use of procurement policies that incorporate environmental considerations, and the presence of recycling and packaging policies. Lastly, there was an appreciation that progressing an environmental sustainability agenda is very much a team activity that involves multiple stakeholders. These stakeholders include not only the event owners and managers and their staff/ volunteers, but also (and depending on the event) suppliers, contractors, transport providers, event attendees, stallholders, community groups, not-forprofit organizations, and venue/site owners.

Table 4

Focus of Environmentally Sustainable Practices by Category ( $n=26$, Multiple Responses Permitted)

\begin{tabular}{lcc}
\hline Practice Category & No. of Responses & \% of Respondents \\
\hline Waste & 25 & $96.2 \%$ \\
Attendee behavior & 20 & $76.9 \%$ \\
Transport & 19 & $73.1 \%$ \\
Energy usage & 18 & $69.2 \%$ \\
Water usage & 16 & $61.5 \%$ \\
Greenhouse gas emissions & 15 & $57.7 \%$ \\
Contractor management & 15 & $57.7 \%$ \\
Procurement & 13 & $50 \%$ \\
Biodiversity/site environmental protection & 8 & $30.8 \%$ \\
\hline
\end{tabular}




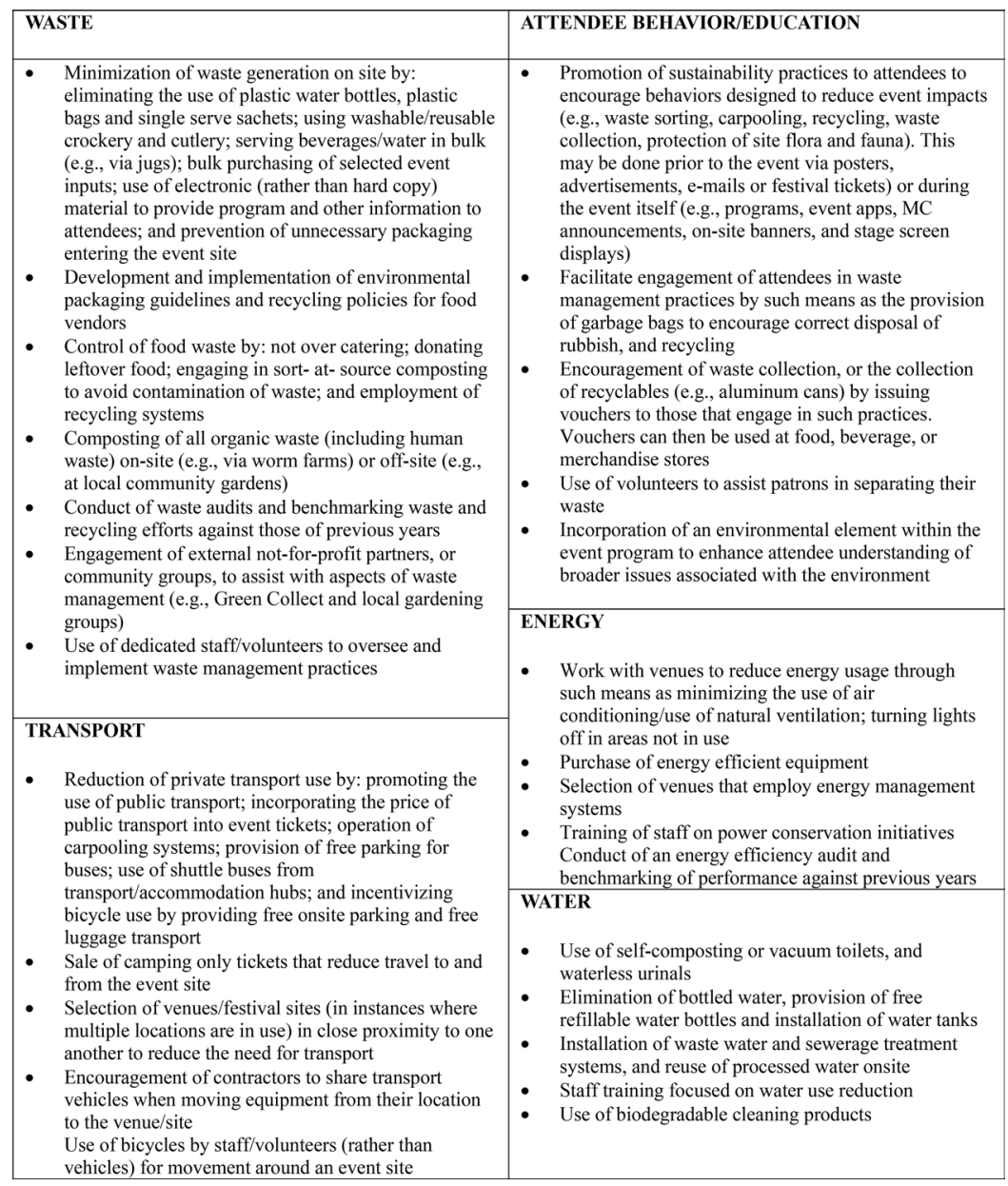

Figure 1. Environmentally sustainable practices in the areas of waste, transport, attendee behavior/education, energy, and water $(n=26)$.

\section{Approaches to Measuring an Event's Environmental Performance}

As is evident in Table 5, a number of techniques were being employed by event owners and managers to measure the environmental performance of their events. Measurements related to an event's waste management practices appear to be the major area of focus, with $80.8 \%$ of respondents calculating both the volume/weight of waste created and the percentage of waste recycled, reused, or composted. It is noteworthy that a not insubstantial number of the responding events (11.5\%) were failing to engage at all with the measurement process.

\section{Factors Serving to Inhibit or Facilitate Environmentally Sustainable Practices}

Respondents were asked to state the barriers they faced in implementing environmentally sustainable practices. This resulted in three key factors being identified. The first of these, which accounted for more than half of all comments (13 respondents), was a lack of resources. Although such comments predominantly concerned financial resources, respondents also mentioned a lack of human resources to progress environmental initiatives. Indicative of such concerns is the following quote: 


\begin{tabular}{|c|c|}
\hline GREENHOUSE GAS EMISSIONS & CONTRACTOR MANAGEMENT \\
\hline $\begin{array}{l}\text { - Use of biofuels and green power sources (e.g., solar) } \\
\text { - Assessment of all event consumables in terms of their } \\
\text { greenhouse gas emissions } \\
\text { Offsetting of an event's carbon emissions through: } \\
\text { onsite tree planting; purchasing of carbon offsets; } \\
\text { payment by attendees of an optional "green fee," } \\
\text { which is used for carbon offsetting } \\
\text { - Collection, and benchmarking (against previous years) } \\
\text { of greenhouse gas emissions data }\end{array}$ & $\begin{array}{l}\text { - Selection of contractors based on their demonstrated } \\
\text { alignment with an event's environmental values } \\
\text { - Inclusion of environmental criteria in contractor } \\
\text { procurement briefs and in contracts e.g. requirement to } \\
\text { use biodegradable consumables and low energy (LED) } \\
\text { lighting (as applicable) } \\
\text { - Elimination of contractors who fail to adhere to } \\
\text { environmental sustainability practices } \\
\text { - Provision of awards to environmentally responsible } \\
\text { stall holders } \\
\text { Education of contractors regarding the event's } \\
\text { environmental management goals/processes in order to } \\
\text { assist compliance }\end{array}$ \\
\hline PROCUREMENT & $\begin{array}{l}\text { BIODIVERSITY/SITE ENVIRONMENTAL } \\
\text { PROTECTION }\end{array}$ \\
\hline $\begin{array}{l}\text { Development and implementation of a procurement } \\
\text { policy that incorporates environmental criteria. Such } \\
\text { criteria may require that: preference is given to locally } \\
\text { sourced food/services in order to reduce travel miles } \\
\text { associated with their provision; products supplied have } \\
\text { a minimum of recycled content; fair trade or organic } \\
\text { food only is used; event inputs must be sourced from } \\
\text { organizations that are able to establish (often through } \\
\text { some form of accreditation) that their products have } \\
\text { been sustainably sourced } \\
\text { Imposition of a fair trade or organic provision to guide } \\
\text { selection of food or food providers }\end{array}$ & $\begin{array}{l}\text { Development and implementation of site protection } \\
\text { practices (e.g., use of fencing and vehicle mats to } \\
\text { protect vulnerable areas; limitations on vehicle } \\
\text { movements to protect soil and plants; restrictions on } \\
\text { the placement of structures/equipment under tree } \\
\text { canopies to protect their root systems; imposition of } \\
\text { "exclusion zones" to protect selected areas in periods } \\
\text { of wet weather; and consideration given in site design } \\
\text { to controlling water runoff into water courses } \\
\text { - Use of volunteers to engage in site rehabilitation } \\
\text { during both the event period and in nonevent periods } \\
\text { (e.g., weed removal, tree planting, grass replacement, } \\
\text { plantings along water courses) } \\
\text { Enhancement of site and surrounding area } \\
\text { environment by placing wildlife nesting boxes in trees } \\
\text { and the creation of wildlife corridors }\end{array}$ \\
\hline
\end{tabular}

Figure 2. Environmentally sustainable practices in the areas of greenhouse gas emissions, procurement, contractor management, and biodiversity/site environmental protection $(n=26)$.

Table 5

Measurement Techniques Used by Events in Benchmarking Environmental Performance ( $n=26$, Multiple Responses Permitted)

\begin{tabular}{lcc}
\hline Measurement Technique & No. of Responses & $\%$ of Respondents \\
\hline Volume/weight of waste created & 21 & $80.8 \%$ \\
Percentage of waste recycled/reused/composted & 21 & $80.8 \%$ \\
Liters of water used & 14 & $53.8 \%$ \\
Percentage of event inputs sourced locally & 12 & $46.2 \%$ \\
Types of transport & 12 & $46.2 \%$ \\
Kilowatts of mains energy used & 11 & $42.3 \%$ \\
Liters of fuel used & 70 & $38.5 \%$ \\
Percentage of event inputs that meet environmental procurement benchmarks & 7 & $26.9 \%$ \\
Greenhouse gas emissions & 7 & $26.9 \%$ \\
Greenhouse gas emissions by specific areas (e.g., transport) & 6 & $26.9 \%$ \\
Mains/bottled gas usage & 4 & $23.1 \%$ \\
Volume of waste water produced & 4 & $15.4 \%$ \\
Other & 3 & $15.4 \%$ \\
We do not currently measure our environmental impact & $11.5 \%$ \\
\hline
\end{tabular}


Our biggest hurdle is "dollars" to ensure we meet all the required/desired standards, plus staff or volunteers to assist. Our event has grown so quickly in its 4 years of operation. It has grown to be one of the biggest events in the area but has minimal funding from our local council and relies heavily on an overstretched business community who have little to spend on sponsorship and are expected to support so many events in our region. Our budget is extremely tight and most of our time is spent on sourcing new sponsors and donated products just to make the bare essentials happen and still produce a quality event for our community. If there was government funding available for events to ensure they hired a dedicated "environmental impact officer” to organize the necessary resources and assess the impacts, events would be more efficient and definitely more environmentally friendly on all levels.

The second barrier, which was noted by four respondents, was a general lack of understanding, determination, and commitment to the need for sustainable actions among various event stakeholders. It was suggested that there is a level of "ignorance" and "apathy," and even "short sightedness" within the industry, as to the capacity of events to act in this area. It was also noted that some event owners and managers, as well as event funding bodies, were of the view that "environmental practice is not . . integral" to an event's operations. The final set of comments (noted by four respondents) highlighted matters linked to "patron ignorance" of sustainable practices and the subsequent impact that it had in respect of an event's environmental performance. For example, it was noted that event attendees who failed to dispose of waste correctly, even after the event had made provisions for this and promoted this fact, impacted significantly on an event's recycling efforts.

Factors facilitating environmentally sustainable practices were found to be of two primary types. The first concerned the level of commitment of the event organization to environmental sustainability, mentioned by 12 respondents. In this context, one respondent drew attention to the importance of a "visionary promoter," while another noted the importance of "top down and entire organization belief, drive and enthusiasm for striving to be the best we possibly can be in the field of sustainable event management." In addition to internal organizational drive, eight respondents commented on the role of selected stakeholders in facilitating their respective event's move towards environmental sustainability. In particular, the role of both a supportive and environmentally conscious host community and attendees was noted, as was the willingness of stallholders and contractors to assist/ play a role in the event's environmental practices.

\section{Issues Linked to Future Progress in Environmental Sustainability}

The final section of the questionnaire gave respondents the opportunity to comment on the current state of the industry and how sustainability in event management might be further progressed. Even though this section was not well responded to, those comments that were made emphasized the importance of external forms of assistance from such sources as local government. Other matters that were raised included: the need for legislation in the area; the importance and availability of education and training; the development of mechanisms for the sharing of information between events; and the need for environmental management of events to be seen more as a core management concern, rather than an optional consideration. In the context of this last point one respondent noted: "the question needs to change from 'why are you doing it?' to 'why aren't you doing it?' At the moment the spotlight is on events that make an effort in sustainable practices. This needs to change to the reverse.” Finally, asked specifically about the role of external validation and whether there is merit in requiring events to have their environmental performance measured and validated by external bodies, $57.7 \%$ of respondents saw value in such a practice. Although recognizing that such an action might be a value to the sector, this view was tempered with concerns centered on time and cost.

\section{Discussion and Conclusions}

The intent of this study was to both add to the limited literature on the increasingly critical issue of environmental sustainablity in the planning and management of public events, and to aid in informing future industry practice in the area. In order to 
fulfill this role, information was sought regarding a number of matters. The first of these concerned the key forces acting to underpin environmental sustainability actions. These were identified as (in order of significance): event operating philosophies/ values; attendee and local community expectations; requirements of councils and permissory bodies; reductions in production costs; and the expectations of sponsors. It is noteworthy that the first and most highly rated of these considerations is internal to the event organization itself. This finding supports Yuan's (2013) view that event organizers need to be values driven to effectively engage with the concept of environmental sustainability. It also suggests that actions in this area are more proactive than reactive and result from a genuine desire to reduce or eliminate environmental impacts. Results here also indicate that matters linked to financial considerations such as production costs and the ability to attract sponsors do not feature as strongly as might be expected in the decision by event owners and managers to act in this area.

A diverse range of practices linked to environmental sustainability were identified through this study. The broad areas in which most respondents were found to be active (in order of significance) were: waste, attendee behavior/education, transport, energy, and water. It is noteworthy that the first four of these categories also featured most strongly when respondents were asked to nominate the challenges they currently faced in pursuing an environmental sustainability agenda. This would seem to indicate that event owners and managers would benefit from more developed, or new, practices specific to these areas. Further, when viewed collectively, the practices identified in this enquiry draw attention to the importance of organizational learning, and the significance of policies, procedures, guidelines, and communication tools in underpinning "best practice” in environmental sustainability.

Although the findings revealed the majority of events were undertaking environmentally sustainable practices across a range of areas, it was found that efforts at measuring environmental performance were limited. Only the areas of waste and water usage were being assessed by more than $50 \%$ of participating events. This being the case, it can be reasonably argued that the events examined here are restricting their ability to quantify the outcomes of their environmental sustainability practices, and as a consequence, their capacity to improve their future performance. The reasons for this are unclear; however, given that only a small percentage of events (8\%) mentioned measurement of environmental impacts as a major challenge (see Table 2), it may be that there is a lack of appreciation of the value of measurement in refining practice.

Three main inhibitors were identified by respondents as impacting their efforts to progress an environmental sustainability agenda. These were resources, commitment on behalf of event owners and managers, and attendee behavior. The first of these, which accounted for approximately $60 \%$ of the responses given, is not surprising. Any engagement with an environmental agenda is likely to involve direct financial and staffing costs, as well as indirect costs in the form of the time it takes to acquire the knowledge to implement practices in the area. This finding is in line with previous studies that identified resources as a significant constraint on environmental sustainability practice (Mair \& Laing, 2012; Pelham, 2011). It should be noted here, given this finding, that resources were cited by only $15 \%$ of respondents when asked to nominate their main challenges when pursuing an environmental sustainability agenda (see Table 2). This apparent contradiction may be due to the way this question was phrased, with respondents believing they needed to state matters directly associated with the environmental practices that they had in place/were confronting, rather than more general considerations such as a lack of resources.

The degree of commitment of event owners and managers to an environmental sustainability agenda was cited by a small number of respondents (four) as acting to restrict their efforts in the area. Although such a result is a little surprising given the "best practice" nature of the sample used, it is not inconsistent with prior research that found that event owners/managers do not always understand or value the importance of environmental sustainability (Paterson \& Ward, 2011; Stettler, 2011).

The third area to which respondents drew attention was that of attendee behavior, most particularly in the context of engagement with waste management practices. This might indicate that event owners and managers face challenges in developing 
mechanisms to effectively involve patrons in the processes that are being employed, something that prior studies have drawn attention to (Harvey, 2009; Izawa, 2012; Mair \& Laing, 2012; Stettler, 2011). This finding also highlights the fact that there are constraints on the level of control that event owners and managers can exert in some of the areas in which they seek to reduce their environmental impacts.

Factors identified as facilitating the environmental sustainability efforts of participating events were found to fall into two major groupings: organizational commitment and effective engagement with selected stakeholders. Organizational commitment has been identified in previous research, conceptualized as getting "buy in" and "leadership from the top” (Harvey, 2009; Mair \& Laing, 2012; Stettler, 2011). Similarly, respondents in this study used terms such as "consciousness" and "dogged determination” when describing their event organization's efforts in pursuing a sustainability agenda. It is noteworthy that this result further supports this study's earlier finding that event values and principles are key to efforts in the environmental sustainability area. Another factor of note identified as playing a role in facilitating action in this area was the maintenance of effective relationships with supportive external stakeholders. In this regard, respondents emphasized the importance of having stakeholders "on the same page" as they pursue their environmental goals. This finding is in line with those of Andersson and Getz (2008) and Laing and Frost (2010).

Some of the matters raised in the small number of responses received as to future progress in the area of environmental sustainability can arguably be seen as problematic in practice, in particular, the use of legislation specific to this aspect of event management. However, it is noteworthy that over $50 \%$ of respondents were supportive of the use of some form of external validation of their environmental sustainability efforts. This would seem to suggest that an opportunity exists to further encourage public events to engage with environmental benchmarking efforts such as the previously cited international standard for sustainable event management-ISO 20121.

Although acknowledging that this study is exploratory in nature, its use of "best practice" cases has nonetheless served to produce findings that contribute meaningfully to the developing discourse around environmentally sustainable event management. Additionally, the outcomes of this inquiry have value to public event owners and managers seeking to progress their engagement with environmental practices. In particular, it provides them with an understanding of the range of sustainable actions currently in use in the key areas of attendee behavior/education, waste management, energy and water usage, transport, greenhouse gas emission reduction, contractor management, procurement, and biodiversity/site environmental protection. Further, it provides insights into the approaches they can employ to measure and subsequently improve their environmental performance. This study also highlights several challenges to adopting best practice, including the need for broad stakeholder buy in and commitment to environmental sustainability, and the value of a visionary event owner or manager in driving action in this increasingly critical area of public event management.

The study's findings also serve to highlight areas where future research is warranted. In particular, waste management, energy management, attendee behavior/education, and transport were noted as key areas where respondents faced major challenges. It is to these priority areas that researchers should consider directing their attention as they seek to develop improved environmentally sustainable practices and strategies. Additionally, given that the measurement of environmental outcomes was limited and often constrained to specific areas-most particularly waste-further research is needed to understand why this is the case, and what is required to encourage greater participation in the measurement of environmental performance more generally. Overall, these areas represent critical challenges for public event owners and managers seeking to meaningfully engage with and advance "best practice" in environmental sustainability in public events.

Finally, while this study has sought to identify "best practice" in the area of environmental sustainability across a number of public events, the concept of what constitutes "best practice" is a dynamic one. Therefore, there is a need for researchers to regularly engage with this issue and to communicate their findings to event owners and managers. As regards the latter point, the best means of creating a conduit between researchers and event 
owners and managers for the purpose of conveying these findings — on an ongoing basis—-needs to be determined if research is to play a role in advancing practice. One way of achieving this, which requires further examination, is the use of organizations already operating to progress environmentally sustainable event management, such as the previously cited Sustainable Event Alliance (2018) and A Greener Festival (2017).

\section{References}

A Greener Festival. (2017). Who are we? Retrieved from http://www.agreenerfestival.com/about-us/

Adema, K. L., \& Roehl, W. S. (2010). Environmental scanning the future of event design. International Journal of Hospitality Management, 29(2), 199-207.

Allen, J., O’Toole, W., Harris, R., \& McDonnell, I. (2011). Festival and special event management (5th ed.). Brisbane, Australia: John Wiley.

Andersson, T. D., \& Getz, D. (2008). Stakeholder management strategies of festivals. Journal of Convention and Event Tourism, 9(3), 199-220.

Andersson, T. D., \& Lundberg, E. (2013). Commensurability and sustainability: Triple impact assessments of a tourism event. Tourism Management, 37, 99-109.

Arcodia, C., Cohen, S. A., \& Dickson, C. (2012). Accrediting sustainable event practice. In Eduardo Fayos-solà (Ed.), Knowledge management in tourism: Policy and governance applications (Bridging Tourism Theory and Practice, Volume 4, pp. 209-218). Bingley, UK: Emerald Group Publishing Ltd.

AsiaOne. (2016). Fort Canning Green closed for returfing. Retrieved from http://www.asiaone.com/News/ AsiaOne\%2BNews/Singapore/Story/A1Story20110301265801.html

Bottrill, C., Papageorgiou, S., \& Jones, M. (2009). Jam packed, part 1: Audience travel emissions from festivals. Retrieved from http://www.sustainable-event-alliance. org/wp-content/uploads/2011/04/jb-TravelReport-smmay09.pdf

Collins, A., \& Cooper, C. (2017). Measuring and managing the environmental impact of festivals: The contribution of the Ecological Footprint. Journal of Sustainable Tourism, 25(1), 148-162.

Collins, A., \& Flynn, A. (2008). Measuring the environmental sustainability of a major sporting event: A case study of the FA Cup Final. Tourism Economics, 14(4), 751-768.

Collins, A., Munday, M., \& Roberts, A. (2012). Environmental consequences of tourism consumption at major events: An analysis of the UK stages of the 2007 Tour de France. Journal of Travel Research, 51(5), 577-590.

Dávid, L. (2009). Environmental impacts of events. In R. Raj \& J. Musgrave (Eds.), Event management and sustainability. Wallingford, UK: CABI.
Draper, J., Dawson, M., \& Casey, E. (2011). An exploratory study of the importance of sustainable practices in the meeting and convention site selection process. Journal of Convention \& Event Tourism, 12(3), 153-178.

Ekins, P. (2011). Environmental sustainability: From environmental valuation to the sustainability gap. Progress in Physical Geography: Earth and the Environment, 35(5), 629-651.

Event Industry Council Sustainability Initiative. (2017). About us. Retrieved from http://www.eicsustainability. org/?page=AboutUS

Gallagher, A., \& Pike, K. (2011). Sustainable management for maritime events and festivals. Journal of Coastal Research, 61, 158-165.

Getz, D. (2010). The nature and scope of festival studies. International Journal of Event Management Research, 5(1), 1-47.

Goldblatt, S. (2012). The complete guide to greener meetings and events. Hoboken, NJ: John Wiley and Sons.

Goodland, R. (1995). The concept of environmental sustainability. Annual Review of Ecological Systems, 26, $1-24$.

Harris, R. (2010). Educating communities for a sustainable future-Do large scale sporting events have a role? Retrieved from https://www.uts.edu.au/sites/default/files/ LargeScaleSportingEventsDevelopment.pdf

Harvey, E. (2009). Greening Live Earth UK. In R. Raj \& J. Musgrave (Eds.), Event management and sustainability (pp. 195-205). Wallingford, UK: CABI.

Henderson, S. (2011). The development of competitive advantage through sustainable event management. Worldwide Hospitality and Tourism Themes, 3(3), 245-257.

International Standards Organization. (2015). ISO 20121: Event sustainability management system. Retrieved from http://www.iso20121.org/

Izawa, M. (2012). Greening event goers at the 2010 FIFA World Cup: A user perspective assessment of sustainable transport strategies. Retrieved from http://ecommons. cornell.edu/bitstream/1813/31381/1/mri5.pdf

Jones, M. (2014). Sustainable event management: A practical guide (2nd ed.). Oxon, UK: Routledge.

Laing, J., \& Frost, W. (2010). How green was my festival: Exploring challenges and opportunities associated with staging green events. International Journal of Hospitality Management, 29(2), 261-267.

Lamberti, L., Fava, I., \& Noci, G. (2009). Assessing and monitoring the performance of a sustainable event. In R. Raj \& J. Musgrave (Eds.), Event management and sustainability. Wallingford, UK: CABI.

Lawton, L. J. (2009). Birding festivals, sustainability, and ecotourism: An ambiguous relationship. Journal of Travel Research, 48(2), 259-267.

Lawton, L. J., \& Weaver, D. (2010). Normative and innovative sustainable resource management at birding festivals. Tourism Management, 31(4), 527-536.

Mair, J., \& Jago, L. (2010). The development of a conceptual model of greening in the business events tourism sector. Journal of Sustainable Tourism, 18(1), 77-94. 
Mair, J., \& Laing, J. (2012). The greening of music festivals: Motivations, barriers and outcomes. Applying the Mair and Jago model. Journal of Sustainable Tourism, 20(5), $683-700$.

Mair, J., \& Laing, J. H. (2013). Encouraging pro-environmental behaviour: The role of sustainability-focused events. Journal of Sustainable Tourism, 21(8), 1113-1128.

Merrilees, B., \& Marles, K. (2011). Green business events: Profiling through a case study. Event Management, 15(4), 361-372.

Moldan, B., Janouskova, S., \& Hak, T. (2012). How to understand and measure environmental sustainability: Indicators and targets. Ecological Indicators, 17, 4-13.

Morelli, J. (2011). Environmental sustainability: A definition for environmental professionals. Journal of Environmental Sustainability, 1(1), 1-9.

Neuman, W. (2003). Social research methods. Boston, MA: Pearson Education.

O’Rourke, S., Irwin, D., \& Straker, J. (2011). Dancing to sustainable tunes: An exploration of music festivals and sustainable practices in Aotearoa. Annals of Leisure Research, 14(4), 341-354.

Paterson, M., \& Ward, S. (2011). Roundtable discussion: Applying sustainability legislation to events. Worldwide Hospitality and Tourism Themes, 3(3), 203-209.

Patton, M. Q. (2002). Qualitative research and evaluation methods (3rd ed.). Thousand Oaks CA: Sage.

Pelham, F. (2011). Will sustainability change the business model of the event industry? Worldwide Hospitality and Tourism Themes, 3(3), 187-192.

Raj, R., \& Musgrave, J. (Eds.). (2009). Event management and sustainability. Wallingford, UK: CABI.

Rapley, T. (2013). Sampling strategies in qualitative research. In U. Flick (Ed.), The Sage handbook of qualitative data analysis. London, UK: Sage. Retrieved from http://methods.sagepub.com/book/the-sage-handbookof-qualitative-data-analysis/n4.xml

Robertson, M., Rogers, P., \& Leask, A. (2009). Progressing socio-cultural impact evaluation for festivals. Journal of
Policy Research in Tourism, Leisure and Events, 1(2), 156-169.

Rodrigues, A. (2016, March 22). The United Nations, sport and the environment. The New Federalist. Retrieved from https://www.thenewfederalist.eu/the-united-nationssport-and-the-environment

Stettler, S. L. (2011). Sustainable event management of music festivals: An event organizer perspective. Retrieved from https://pdxscholar.library.pdx.edu/open_access_etds/257

Sustainable Event Alliance. (2018). Welcome to the sustainable event alliance. Retrieved from http://sustainableevent-alliance.org/

Sutton, P. (2004). A perspective on environmental sustainability: A paper for the Victorian Commissioner of Environmental Sustainability. Melbourne, Australia: Green Innovations.

Thornberg, R., \& Charmaz, K. (2013). Grounded theory and theoretical coding. In U. Flick (Ed.), The Sage handbook of qualitative data analysis. London, UK: Sage. Retrieved from http://sk.sagepub.com/reference/the-sagehandbook-of-qualitative-data-analysis/i1020.xml

United Nations Environment Program. (n.d.). Music and environment initiative. Retrieved from https://songsforee. wordpress.com/2016/11/22/un-music-and-environmentinitiative/

Wong, I. A., Wan, Y. K. P., \& Qi, S. (2014). Green events, value perceptions, and the role of consumer involvement in festival design and performance. Journal of Sustainable Tourism, 23(2), 294-315.

Wrap. (2018). Sustainable event management case studies. Retrieved from http://www.wrap.org.uk/content/sus tainable-event-management-case-studies

Yuan, Y. Y. (2013). Adding environmental sustainability to the management of event tourism. International Journal of Culture, Tourism and Hospitality Research, 7(2), 175-183.

Zifkos, G. (2015). Sustainability everywhere: Problematising the "sustainable festival" phenomenon. Tourism Planning and Development, 12(1), 6-19. 